\title{
Isolation: Serious, Infectious Diseases
}

\begin{abstract}
All persons staying in hospitals should be protected against exposure to infectious agents, and especially to high-risk, dangerous agents - that pose a risk to health and life. It is not acceptable to place a patient with a known high-risk, serious infection in the same hospital room as other patients (WHO). In this chapter, the preparedness of isolation capacity and escalation of hospital beds for patients with dangerous infections are described.
\end{abstract}

\section{Keywords}

Isolation capacity · Cohort isolation - Contact isolation · Airborne isolation Escalating increased need of beds

\subsection{Purpose}

- Describe the need for preparedness concerning isolation capacity in case of serious outbreaks and escalating need for isolation beds.

- Evaluate in cooperation with other hospitals (regional, national) the acute need for isolation capacity.

- Evaluate measures to handle outbreaks during normal epidemiological situation, smaller outbreaks and large outbreaks [1-3].

\subsection{Comprise}

- The hospital' management, infection control personnel and all persons responsible for the emergency plan and for implementation of the plan. 


\subsection{Responsibility}

The hospital's management, emergency group and infection control personnel provides updated written information concerning isolation capacity and types in the hospital and the actual region.

The decision of increased need of isolates, more special trained personnel and equipment is made in cooperation with emergency team and with regional and national infection control coordinators.

Department management has the overall responsibility for ensuring that isolates are functioning as they should and that routines are followed.

\subsection{Practical Measures [4]}

\subsubsection{Patients with Infections: Need for Isolation Units in Hospitals}

Normal situation - concerning infectious diseases caused by bacteria-is dependent on endemic situation, use of antibiotics and development of resistance.

- In Scandinavian countries like Norway, at least $20 \%$ of hospitalized patients may have infections - community or institutional associated-and 20-30\% receive antibacterial agents, prophylactically or therapeutic [4-8]. Approximately 20\% of all admitted patients need at minimum a single room due to risk of transmission of infections. At least $10 \%$ of nosocomial infections are transmitted via droplets-airborne [4-8].

- At least 5\% of invasive Escherichia coli in Scandinavia were resistant to thirdgeneration cephalosporins in 2016, while up to 50\% were resistant in countries in the south of Europe [9]. The EARS-Net surveillance data for 2016 showed a pattern of more resistant, invasive bacteria in the south than north of Europe, for Klebsiella pneumonia, Acinetobacter sp., MRSA and Enterococcus faecium [10].

- The consumption of antibiotics in the community was up to 20 DDD per 1000 inhabitants per day in Scandinavia, while up to 36 DDD per day in the south of Europe in 2016 [10].

- The consumption of antibiotics for systemic use in the hospital sector was 1.4 2.1 DDD per 1000 inhabitants per day, in Norway, Sweden and Denmark and higher, up to 2.9 DDD, in Finland that included remote primary healthcare centres and nursing homes [10]. The population-weighted mean consumption of antibiotics for systemic use in the hospital sector in Europe/EEA was 2.0 DDD per 1000 inhabitants per day [10].

Local outbreaks of, for example, norovirus, rotavirus, influenza virus, metapneumovirus, respiratory syncytial virus (RSV) or resistant bacteria from home and abroad double the need for isolates or single rooms in hospitals in periods. 
Influenza pandemics it has previously been estimated that in larger outbreaks, $0.3 \%$ of the population will need hospitalization, and approximately $13 \%$ need outpatient treatment. Capacity and readiness for escalating - if needed-should be calculated and included in emergency preparedness plans in and outside hospitals. In such cases it may be appropriate to request predefined, newer hotels or healthcare institutions.

For example, the need in the Oslo region with about 800,000 inhabitants would be 2400 additional hospitalizations of isolation-needing patients over a short period of 1-2 months. If the average stay would be 10 days and the patients were equally distributed over this period (which is not the situation), the need at any time would be approximately 400 extra isolate beds.

\subsubsection{Pandemic Flu AH1 N1 2009: Experience from Norway}

The pandemic flu AH1N1 came quickly and disappeared relatively rapidly-from spring to autumn of 2009-in Norway [5, 6, 11-17]. There was a tendency for a two-phase epidemic development, with a slight top during weeks 28-32 [11]. Microbiological detection of virus (AH1N1) was quickly established but never exceeded 2800 positive findings on a weekly basis in a population of ca. five million inhabitants; see Fig. 83.1 [11].

On a national basis, the number of hospitalized patients per day in the peak period was approximately 90 patients, and 20-30 patients were in intensive care units (Fig. 83.2).

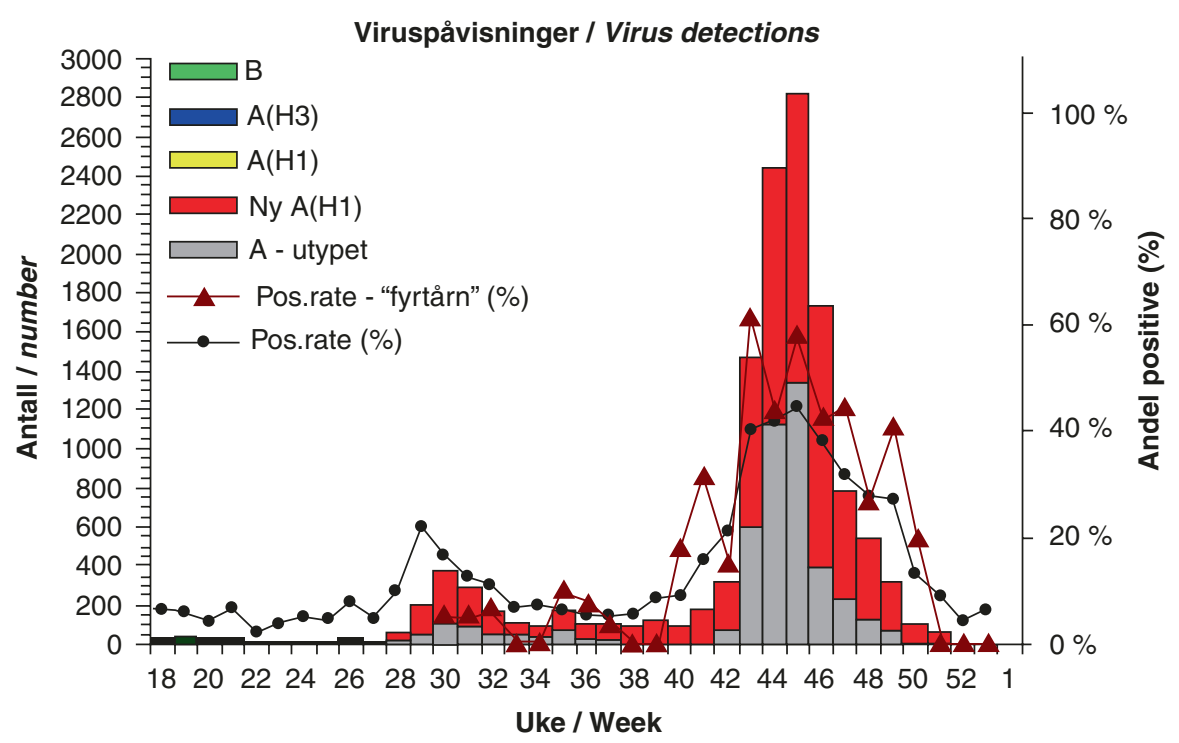

Fig. 83.1 Pandemic influenza had a two-phase development from spring to autumn 2009. Source: National Public Health Norway [11] 


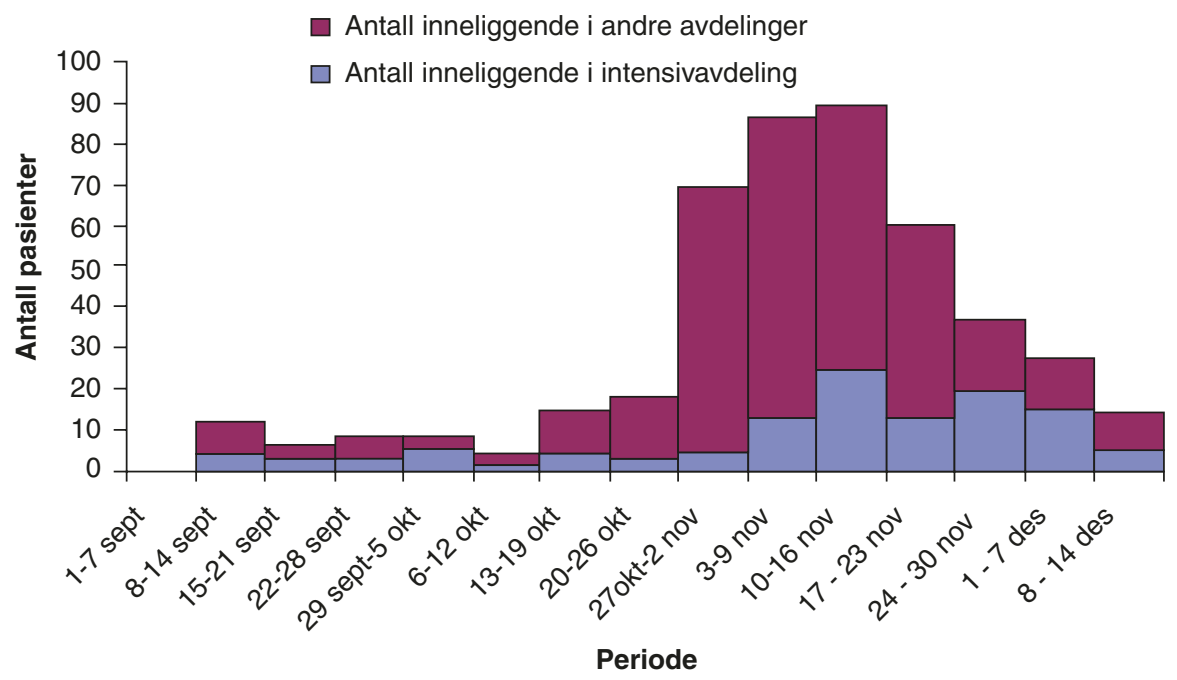

Fig. 83.2 Number of hospitalized patients with laboratory-detected pandemic influenza A H1N1 from 1 September 2009. Patients: blue admitted to ICUs and red to other departments. Source: National Public Health Norway [11]

\section{Nye pasienter per uke ved OUS-Ullevål - og kumulativt antall døde}

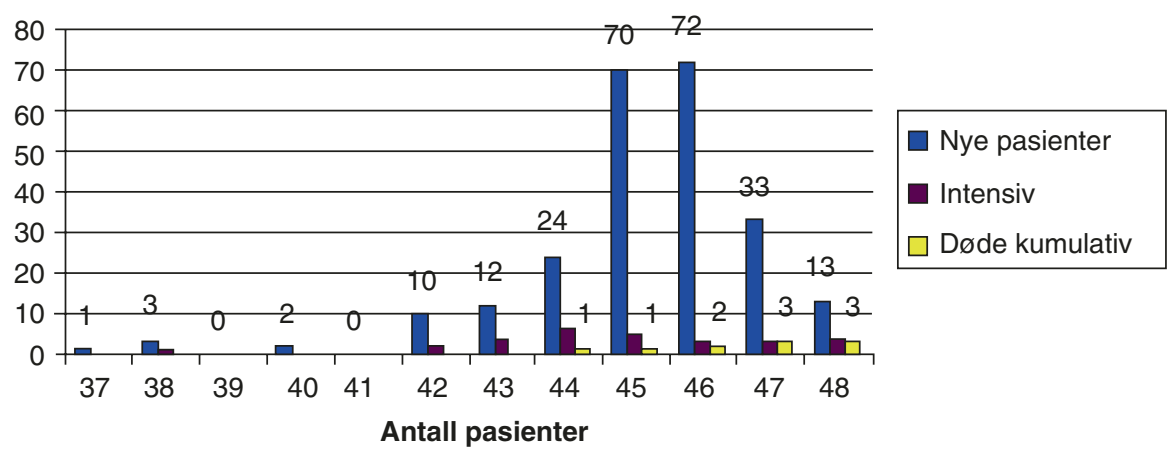

Fig. 83.3 Number of new patients with influenza AH1N1 (blue), admitted to OUS-Ullevål University Hospital per week; number of patients in intensive units (red) - and cumulatively number of deaths (yellow). Source: BM Andersen, OUS—Ullevål University Hospital 2009 [5, 6]

OUS—Ullevål University Hospital, Oslo, is the main hospital for about 800,000 inhabitants in the southeast of Norway. There were a maximum of 72 patients admitted to the hospital per week (46), because of influenza AH1N1, including ca. 10 patients at the intensive care units per week (Fig. 83.3) [5, 6]. There was no capacity shortage due to a ready distribution system for patients, as well as a plan for cohort isolation at a separate hospital building $[5,6]$. Three patients were registered dead because of the pandemic at Ulleval; one of them was dead on arrival $[5,6]$. 


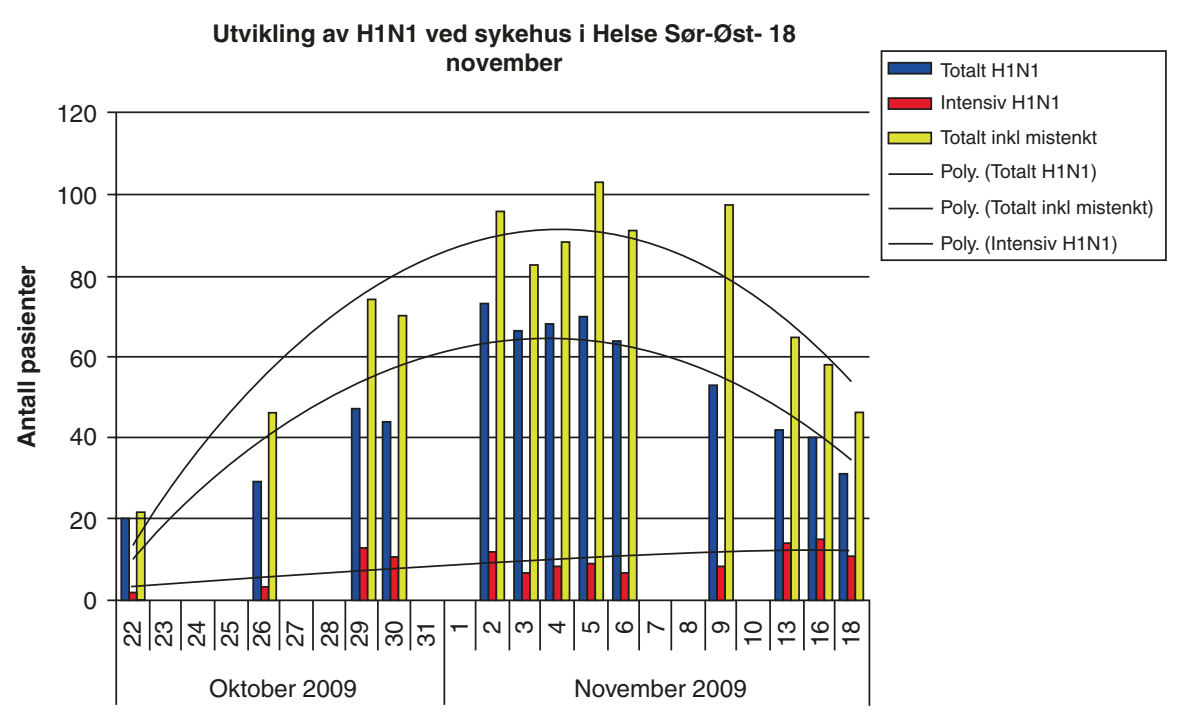

Fig. 83.4 Number of patients with influenza AH1N1 (blue), admitted to hospitals in the health region southeast of Norway (ca 2.5 million inhabitants) per week; number of patients in intensive units (red) - and total number, included suspect cases (yellow) from October to November 2009. Source: BM Andersen, OUS—Ullevål University Hospital 2009 [5, 6]

Including all hospitals in the health region southeast of Norway (2.5 million inhabitants), there were around 100 hospitalized influenza patients daily during the period 2-9 November and then a rapid decline (Fig. 83.4) [4, 5]. Between 10 and 18 intensive patients were treated for pandemic flu each day during this period.

Experiences from this pandemic showed that the calculated scenarios did not agree with the facts, either regarding the number of infected (probably), hospital admissions, intensive care or death rate.

\subsubsection{Isolates: Capacity}

\subsubsection{Number and Status $[5,6,11-17]$}

It is important to have an overview of the number and types of isolates for infectious diseases in a radius of at least $100 \mathrm{~km}$ around densely populated areas. The isolates should be checked at least once a year that they function according to the mode of use. Isolates for airborne infectious agents should have a negative air pressure, sluice and separate bathroom disinfection room with decontaminator, and contact isolates should also have a separate bathroom disinfection room with decontaminator and through-put and should have some degree of negative air pressure in relation to corridor, etc.

Single room with toilet/shower. It is essential to have a list available on the number of well-equipped rooms that can be used for contact isolation. 
A large hospital like Ullevål University Hospital with approx. 800 somatic beds have $41(5.1 \%$ ) isolation units for airborne infections (of which 20 for children), 25 contact isolates $(3.1 \%)$ and 74 single beds $(9.3 \%)$.

Isolation requirement in case of minor outbreaks under normal epidemiologically situations:

- Patients: Under normal circumstances, the number of satisfactory isolates should cover the usual needs of the population, if also included the use of other hospitals in the area, flexible. Most outbreaks of serious epidemics are related to a few patients, $1-5$.

- Close contact/exposed/carriers: Short-term isolation may be applicable to persons exposed to infection by diphtheria (adults, elderly), plague and possibly anthrax. In some cases, isolation is applicable to infected persons or carriers who cannot take care of themselves/do not follow preventive measures or other conditions that require isolation (e.g., exposure/carrier status of cholera and other intestinal pathogenic microbes, multidrug-resistant bacteria, VHF).

Isolates needed for major outbreaks-serious epidemic in the populationexceeds capacity:

- Escalating situation. An escalation plan must be available, with an overview of hospitals, other health institutions, hotels, etc. that can be predefined and staffed by appointment. Fixed, annual technical control must be carried out. It should not be far away from core areas but sheltered.

- If cohort treatment of patients with the same microbiological diagnosis-put patients in the same room; it will facilitate the care situation and save personal protection equipment (PPE). In case of major outbreaks, the entire departments or hospitals can be dedicated to patients with laboratory-diagnosed infection (see SARS outbreaks in China and Singapore 2003 where they had their own SARS hospitals).

- Avoid long transportation of infection patients. Isolate units should not be far from hospitals that take care of the epidemic (where most cases are occurring). Long transport takes large resources and time and can cause fear in the population.

How to increase the capacity if the outbreak escalates:

Depending on the number of people involved in an outbreak of infection, it should be planned as follows:

- Patients with identical microbiological agent and increased need of hospital treatment-escalate:

- Infection disease wards or intensive units with isolates

- Other suitable departments (area shielded/the building is closed for other patients)

- Other suitable hospitals in the region.

- If necessary - a complete hospital, entire nursing home or pre-arranged/ requested hotel 
- Carriers/exposed/close contacts

- Isolation at home, if possible.

- Isolation at designated buildings, at hospital or at predesignated hotel.

- Note! Nursing homes and similar buildings with common ventilation are not suitable for airborne isolation of exposed, close contacts or infectious carriers because of risk of transmission via air.

- It is assumed that the general minimum requirements for emergency response/ mass isolation are met (see below).

Isolate need for major epidemics/disasters:

In case of war with for instance biological weapons or an unusual epidemic extent/ condition, the need for isolates will be large. Here it will probably be relevant for cooperation between states and countries. In such cases it may be appropriate to request predefined, newer hotels, cf. the Norwegian Health and Social Preparedness Act, §3-1 Requisition [12-17]. A report of 22 February 1984 to the Director General of Health, under review, "Proposal for Planning of Epidemiological Preparedness" by a reference group set up by the Directorate of Health on 30 March 1982. The report states that after the "nature and extent of the disaster," different measures may be needed for the isolation, treatment and care of patients with infectious diseases. "In all these cases, one must assume that the best suited for these purposes are our many and good hotels." It is emphasized that in all parts of the country, preferentially, new hotels should be predesignated for this purpose. Most hotels have a high quality of the building and hygienic standard. They have single and double rooms, most of them with separate bathrooms and toilets, which is of the utmost importance as it facilitates isolation and care. They also have laundry facilities and kitchens, and most have wings that can be shut down. These are qualities that are approaching the requirements of an isolation department. The ventilation should be considered turned off. Ventilation can be done via windows if not large passage of people directly outside (WHO).

General requirements for emergency response/mass isolation—area:

- Fast, mobilizable and flexible.

- Preferably direct access from outside or via closed corridor.

- Preferably one bedroom with a high hygienic standard; sink, bath/shower.

- Access to kitchen or other cooking facilities.

- Can be closed to other parts of the building.

- Preferably not in densely populated areas.

- If situated outside the main hospital, it should be so close that it can be operated from the hospital departments (infectious medicine, intensive, lung, X-ray, sampling, cleaning, textile, purchasing, kitchen, transportation and a number of other service functions).

Need for personnel, equipment, service, transport, etc.:

- An estimate of needed qualified personnel in an escalation plan must be available. 
- Requirements for specific equipment such as respirator, other ventilation equipment, etc. - escalation plan must be available.

- Service plan of service (food, water, laundry, consumables, etc.).

- Plan for cleaning, disinfection and disposal.

- Transport plan (patients, equipment, vehicles, etc.) must be available.

\section{References}

1. Ministry of Labour and Administration. Regulations on protection against exposure to biological factors (bacteria, viruses, fungi and more) in the workplace. FOR OSLO: 1997-12-19 nr.1322.

2. Sehulster LM, Chinn RYW, Ardunio MJ, et al. Guidelines for environmental infection control in health-care facilities. CDC MMWR. 2003;52:1-42.

3. Rutala WA, Weber DJ. Disinfection, sterilization, and control of hospital waste. In: Mandell, Douglas, and Bennets principles and practice of infectious diseases, vol. 2. 8th ed. Philadelphia: Elsevier Churchill Livingstone; 2015. p. 3294-309.

4. Andersen BM, Hochlin K, Lereim I. Serious infections-isolation. In: Handbook in hygiene and infectious diseases for hospitals. Oslo: Ullevål University Hospital; 2008. p. 563-6.

5. Andersen BM. Pandemic flu. In: Handbook in hygiene and infection control for hospitals. Part 1. Fagbokforlaget; 2014. p. 212-36.

6. Andersen BM. Pandemic preparedness 2010-evaluation-pandemic 2009-OUS-Ullevål. 20/12/2010. Attachment to the evaluation report to HSØ from OUS.

7. Andersen BM, Holta Ringertz S, Gullord Petersen T, Hermansen W, Lelek M, Norman BI, Næs B, Tilrem Nystad M, Andersen Rød K, Røed RT, Solheim N, Smidesand IJ, Tandberg S, Halsnes R, Høystad MW. A three-year survey of nosocomial and community-acquired infections, antibiotic treatment and re-hospitalization in a Norwegian health region. J Hosp Infect. 2000;44:214-23.

8. Andersen BM, Rasch M, Hochlin K, Tollefsen T, Sandvik L. Hospital-acquired infections before and after healthcare reorganization in a tertiary university hospital in Norway. J Public Health. 2009;7:1-7.

9. ECDC. Summary of the latest data on antibiotic resistance in the European Union. EARS-Net surveillance data, November 2017.

10. ECDC. Summary of the latest data on antibiotic consumption in the European Union. ESACNet surveillance data, November 2017.

11. National Public Health of Norway. Pandemic reports 2009.

12. Law on Health and Social Preparedness 23 June 2000, No. 56. Oslo: Royal Health and Social Affairs; 2000.

13. Ministry of Social Affairs and Health. National emergency plan for pandemic flu. Oslo; 1999, 2001, 2006, 2009.

14. Ministry of Health and Care Services. Superior National Health and Social Preparedness Plan. Norway; 2007.

15. Regional Plan for Health and Social Preparedness in Health Region East, Norway; 2005.

16. Norwegian Health Directorate. Pandemic planning in municipal health services. Organization, processing, logistics. Draft 26 April 2009.

17. Norwegian Health Directorate. Pandemic planning in the specialist health service. Organization, patient reception and treatment. 2009. 